\title{
Etiology of Pseudarthrosis in Ankylosing Spondylitis: What Is the Main Cause?
}

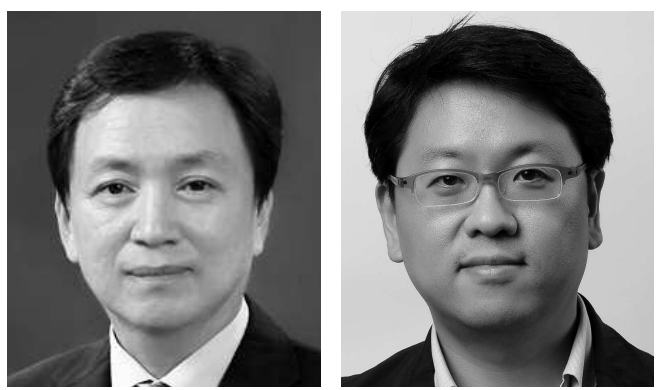

One of the well-known complications in advanced ankylosing spondylitis (AS) is the development of Andersson lesion $(\mathrm{AL})^{1}$. Subsequently, various reports with conflicting terminology appeared in the literature. Spondylodiskitis, which implies inflammatory etiology, was used by some authors $2,3,4$. Others have used the terms destructive vertebral lesion ${ }^{5,6,7,8}$ or spinal pseudarthrosis ${ }^{9,10}$.

The terminological diversity alludes to the varied purported etiologies surrounding AL. The etiologies of extensive AL have been well documented in literature. Various etiologies for the development of AL in patients with AS have been postulated, including infection, inflammation, and trauma. Current consensus is that infection is no longer considered a cause of the AL, because of the lack of positive culture results. Subsequently, etiology of the AL has been open to an ongoing debate between inflammation and trauma.

AS is characterized by spinal inflammation, and it is not surprising that many authors have focused on the inflammatory etiology of AL. Anterior spondylitis such as Romanus lesion comprised marginal erosion of the anterior vertebral corners related to inflammation of the attachment sites of anterior annulus fibrosus (AF) and anterior longitudinal ligament (ALL) in patients with $\mathrm{AS}^{8}$. The erosion becomes enclosed by a sclerotic rim and further healing results in the formation of syndesmophytes, finally resulting in a complete ankylosed segment. It has been postulated that $\mathrm{AL}$ might be exceptional extensions of this inflammatory process ${ }^{3,8,11,12}$. However, many authors disagree since Romanus lesion is an enthesitis limited to the junction of the ALL and $\mathrm{AF}^{6,13}$. Further, Romanus lesion usually affects multiple levels while AL often involves only a single level. Additionally, it has been postulated that one inflammatory process that mainly involves the vertebral endplates of the intervertebral disc is the herniation of nucleus pulposus through the endplates ${ }^{14}$. This inflammatory process is closely related to osteoporosis occurring in longterm AS. The nucleus pulposus is an avascularized tissue, and contact with the vascularized subchondral bone is suspected to provoke a serious inflammatory response ${ }^{15}$. Thus, these inflammatory AL may be more susceptible to stress fractures than others and may eventually progress to pseudarthrosis ${ }^{3}$.

In contrast, Chan, et $a l^{9}$ reported that 3 patients had spondylodiskitis, with serial plain radiographs documenting subsequent healing and fusion across the involved spaces. Several years later, pseudarthrosis appeared at segments previously unaffected by the spondylodiskitis. According to many authors, the AL develops after trauma, rather than inflammation, and is associated with fracture of the spine ${ }^{9}$. The ankylosed and osteoporotic spine in patients with AS is prone to fracture owing to direct minor trauma or to chronic mechanical stress ${ }^{16,17}$. Acute fractures in AS are most commonly observed near the thoracolumbar junction ${ }^{18}$. In a long ankylosed thoracolumbar kyphotic spine, local stresses near the thoracolumbar junction are dramatically high. In addition, repeated stress itself may also lead to a fracture of the ankylosed spine $e^{9,10,19}$. Because the stress fracture level is always the last mobile joint between 2 ankylosed spinal segments, the continued movement at the fracture site eventually contributes to the development of pseudarthrosis ${ }^{20}$.

To date there is no consensus about the cause of extensive $\mathrm{AL}$ or pseudarthrosis formation. It is possible that inflammatory as well as mechanical factors play a role, with mechanical factors including not only trauma, but also factors related to stiff kyphosis, osteoporosis, and short mobile spinal segments ${ }^{10}$.

In this issue of The Journal, Qiao, et al investigated histological findings of pseudarthrosis occurring in a group of patients with AS, with the aim of clarifying the pathogenesis of these extensive $\mathrm{AL}^{21}$. Based on radiologic and pathologic data, Qiao, et al concluded that pseudarthrosis in AS more likely originates from mechanical trauma than from inflammatory process. Many authors have previously attempted to identify the cause of pseudarthrosis with histopathologic correlations of radiologic findings $s^{3,5,9,10,12}$. In this study, Qiao, et al provides a novel, and therefore intriguing, attempt

\section{See Pathogenesis of pseudarthrosis, page 259}


to illuminate the pathologic features of pseudarthrosis: trauma, fibrous repair, and bony repair ${ }^{21}$.

However, Qiao, et al showed various limitations in predicting the cause of pseudarthrosis as mechanical trauma. First, this current study was not a longitudinal cohort study based on continuous observation of AL, but a cross-sectional study based on results from the findings at the time of surgery ${ }^{21}$. Histological findings from lesions showing pseudarthrosis at the time of surgery are likely to be interpreted as traumatic, because histology may change inflammatory to fibrotic over time. There remains the possibility that antiinflammatory drugs, such as nonsteroidal antiinflammatory drugs administered to reduce inflammation before surgery, affect histologic findings in the lesions before operation. Although not actually pathologic findings, the use of antiinflammatory drugs has been reported to improve patients' symptoms and radiologic features ${ }^{3,22}$. Secondly, Qiao, et al excluded 58 patients without severe cord impingement and lesions near the "apex," which was defined as "apical region of global kyphosis ${ }^{21}$." Pseudarthroses in apex or near apex are exposed to stiff kyphosis, which is the most likely determining factor. Thus, researchers who are aware of pseudarthrosis can reasonably predict that AL may be the result of a traumatic etiology in apex or near apex. In particular, it has been reported that the intact sternal-rib complex provides stability to the upper thoracic spine and may not cause neurologic complications even if all 3 columns of the upper thoracic spine are involved $^{23}$. In this case, regardless of the cause of AL, conservative treatment is possible and tissue findings may not be obtained, making it difficult to completely exclude inflammatory processes as a cause. Even where the effect of mechanical trauma is low, if the pathologic findings of pseudarthrosis are related to traumatic etiology, the results and conclusion by Qiao, et al may be more influential ${ }^{21}$. Third, unlike the detailed pathologic findings, Qiao, et al did not adequately explain the radiologic and pathologic correlation with sufficient magnetic resonance (MR) analysis. When analyzing MR findings based on the 3-column theory, details of structures such as the annulus fibrosus, the vertebral body, the anterior longitudinal ligament, the posterior longitudinal ligament, the supraspinous and infraspinous ligaments, the intervertebral joints, ligamentum flavum, and posterior portion of the neural arch must be analyzed, and findings of fracture, soft tissue disruption, canal stenosis, and encroachment must be assessed ${ }^{24}$, because surgical treatment of pseudarthrosis in AS depends on its location, level of involvement, acute or chronic status, structures involved, stability (3-column involvement), displacement, and spinal cord compression ${ }^{24}$. Finally, pseudarthrosis occurring at or near apex is known to occur in patients with high modified Stoke Ankylosing Spondylitis Spine Score and disease duration of $>12$ years ${ }^{12}$. However, 4 out of the 17 patients $(23.5 \%)$ who were included in the current study ${ }^{21}$ had short disease duration of $<5$ years, and for 2 of them, the duration was $<2$ years.
Improving our understanding of pseudarthrosis formation will enable us to provide better treatment for our patients. Readers will benefit greatly from this article ${ }^{21}$, and we hope that proper investigation of AL etiology will help clarify the confusion surrounding treatment and terminology. Additionally, a longitudinal cohort study of AL may put an end to the controversy in the future.

TAE-HWAN KIM 1 , MD, PhD

Department of Rheumatology,

Hanyang University Hospital for Rheumatic Diseases; SEUNGHUN LEE (i), MD, PhD,

Department of Radiology,

Hanyang University Hospital for Rheumatic Diseases, Seoul, Republic of Korea.

Address correspondence to Dr. S. Lee, Department of Radiology,

Hanyang University Hospital for Rheumatic Diseases,

17 Haengdang-Dong, Seongdong-Gu, Seoul 133-792,

Republic of Korea. E-mail: radsh@hanyang.ac.kr

\section{REFERENCES}

1. Andersson O. [Radiographic image of spondylarthritis ankylopoetica]. [Article in Swedish] Nord Med Tidskr 1937;14:2000-3.

2. Kabasakal Y, Garrett SL, Calin A. The epidemiology of spondylodiscitis in ankylosing spondylitis. Br J Rheumatol 1996;35:660-3.

3. Rasker JJ, Prevo RL, Lanting PJ. Spondylodiscitis in ankylosing spondylitis, inflammation or trauma? A description of six cases. Scand J Rheumatol 1996;25:52-7.

4. Simmons EH, Goodwin CB. Spondylodiscitis: a manifestation of ankylosing spondylitis. Orthop Trans 1984;8:165-71.

5. Cawley MI, Chalmers TM, Kellgren JH, Ball J. Destructive lesions of vertebral bodies in ankylosing spondylitis. Ann Rheum Dis 1972;31:345-51.

6. Frank P, Gleeson JA. Destructive vertebral lesions in ankylosing spondylitis. Br J Radiol 1975;48:755-9.

7. Kanefield DG, Mullins BP, Freehafer AA. Destructive lesions of spine in rheumatoid ankylosing spondylitis. J Bone Joint Surg Am 1969;51:1369-75.

8. Romanus R, Yedn S. Destructive and ossifying spondylitic changes in rheumatoid ankylosing spondylitis. Acta Orthop Scand 1952;22:88-91.

9. Chan FL, Ho EK, Fang D, Hsu LC, Leong JC, Ngan H. Spinal pseudoarthrosis in ankylosing spondylitis. Acta Radiol 1987;28:383-8.

10. Fang D, Leong JC, Ho EK, Chan FL, Chow SP. Spinal pseudarthrosis in ankylosing spondylitis. Clinicopathological correlation and the results of anterior spinal fusion. J Bone Joint Surg Br 1988;70:443-7.

11. Kenny JB, Hughes PL, Whitehouse GH. Discovertebral destruction in ankylosing spondylitis: the role of computed tomography and magnetic resonance imaging. Br J Radiol 1990;63:448-55.

12. Dihlmann W, Delling G. Disco-vertebral destructive lesions (so-called Andersson lesions) associated with ankylosing spondylitis. Skeletal Radiol 1978;3:10-6.

13. Arnold MH, Brooks PM, Ryan M, Francis H. A destructive discovertebral lesion: septic discitis, ankylosing spondylitis, or rheumatoid arthritis? Clin Rheumatol 1989;8:277-81.

14. Calin A, Robertson D. Spondylodiscitis and pseudarthrosis in a patient with enteropathic spondyloarthropathy. Ann Rheum Dis 1991;50:117-9.

15. Albert HB, Kjaer P, Jensen TS, Sorensen JS, Bendix T, Manniche C.

Personal non-commercial use only. The Journal of Rheumatology Copyright (C) 2019. All rights reserved. 
Modic changes, possible causes and relation to low back pain. Med Hypotheses 2008;70:361-8.

16. Hitchon PW, From AM, Brenton MD, Glaser JA, Torner JC. Fractures of the thoracolumbar spine complicating ankylosing spondylitis. J Neurosurg Spine 2002;97:218-22.

17. Hunter T, Dubo HI. Spinal fractures complicating ankylosing spondylitis. A long-term follow up study. Arthritis Rheum 1983;26:751-9.

18. Gelman MI, Umber JS. Fractures of the thoracolumbar spine in ankylosing spondylitis. Am J Roentgenol 1978;130:485-91.

19. Shih TT, Chen PQ, Li YW, Hsu CY. Spinal fractures and pseudoarthrosis complicating ankylosing spondylitis: MRI manifestation and clinical significance. J Comput Assist Tomogr 2001;25:164-70.

20. Pettersson T, Laasonen L, Leirisalo-Repo M, Tervahartiala P. Spinal pseudoarthrosis complicating ankylosing spondylitis: a report of two patients. Br J Rheumatol 1996;35:1319-23.
21. Qiao M, Qian BP, Qiu Y, Mao SH, Wang YH. Radiologic and pathological investigation of pseudarthrosis in ankylosing spondylitis: distinguishing between inflammatory and traumatic etiology. J Rheumatol 2019;46:259-65.

22. Sieper J, Baraliakos X, Listing J, Brandt J, Haibel H, Rudwaleit M, et al. Persistent reduction of spinal inflammation as assessed by magnetic resonance imaging in patients with ankylosing spondylitis after 2 years of treatment with the anti-tumour necrosis factor agent infliximab. Rheumatology 2005;44:1525-30.

23. Shen FH, Samartzis D. Successful nonoperative treatment of a three-column thoracic fracture in a patient with ankylosing spondylitis: existence and clinical significance of the fourth column of the spine. Spine 2007;32:E423-7.

24. Wang YF, Teng MM, Chang CY, Wu HT, Wang ST. Imaging manifestations of spinal fractures in ankylosing spondylitis. Am J Neuroradiol 2005;26:2067-76.

J Rheumatol 2019;46:226-8; doi:10.3899/jrheum.180987 